\title{
Reflecting photonics: reaching new audiences through new partnerships - IYL 2015 and the Royal Horticultural Society Flower Show
}

Matthew Posner, Pearl John, Deanna Standen, Natalie Wheeler, Lieke van Putten, et al.

Matthew T. Posner, Pearl V. John, Deanna Standen, Natalie V. Wheeler, Lieke D. van Putten, Nathan Soper, Tina L. Parsonage, Nicholas H. L. Wong, Gilberto Brambilla, "Reflecting photonics: reaching new audiences through new partnerships - IYL 2015 and the Royal Horticultural Society Flower Show," Proc. SPIE 9946, Optics Education and Outreach IV, 994603 (27 September 2016); doi: 10.1117/12.2236977

Event: SPIE Optical Engineering + Applications, 2016, San Diego, California, United States 


\title{
Reflecting Photonics: Reaching new audiences through new partnerships - IYL 2015 and the Royal Horticultural Society Flower Show
}

\author{
Matthew T. Posner*a, Pearl V. John ${ }^{\mathrm{a}}$, Deanna Standen ${ }^{\mathrm{a}}$, Natalie V. Wheeler ${ }^{\mathrm{a}}$, Lieke D. van Putten ${ }^{\mathrm{a}}$, \\ Nathan Soper ${ }^{\mathrm{a}}$, Tina L. Parsonage ${ }^{\mathrm{a}}$, Nicholas H. L. Wong ${ }^{\mathrm{a}}$, Gilberto Brambilla ${ }^{\mathrm{a}}$ \\ ${ }^{a}$ University of Southampton, University Road, Southampton, SO17 1BJ, United Kingdom
}

\begin{abstract}
The 'Reflecting Photonics' show garden was exhibited at the 2015 Royal Horticultural Society (RHS) Flower Show in Tatton Park, UK, to celebrate the International Year of Light and Light-based Technologies. Elks-Smith Garden Design alongside landscapers 'Turf N' Earth' collaborated with researchers, marketing and outreach professionals from the University of Southampton to design, construct and exhibit a photonics-themed garden. The garden and supporting exhibition united science and art to reach new audiences - particularly family groups alongside other key influencers to the young - and showcased the world-leading research in optical fibers at the university in an accessible manner. Researchers and a publicity professional, funded by the EPSRC Centre for Innovative Manufacturing in Photonics, developed an integrated approach to the event's public engagement and marketing. The overarching aim was to influence a positive change in the attitude of the garden visitors towards physics and photonics, with additional focus on promoting careers for women in STEM. The show garden won an RHS Gold Medal award and the coveted 'People's Choice Award' for the best large garden. The project subsequently won the South East England Physics Network Public Engagement Innovation Project Award. Approximately 80,000 visitors saw the garden, with a further three million television viewers on a popular British gardening show. There were also over 75,400 Tweet impressions on social media. This paper discusses the project aims, explores the design of the garden and its relationship with the research, describes the work of the public engagement team, and outlines the impact of the event.
\end{abstract}

Keywords: Optics education, Photonics outreach, Public engagement, Science and gardening, STEAM, Gender diversity in STEM.

\section{INTRODUCTION}

In 2015 the University of Southampton (UoS) partnered with a successful local landscape designer, Elks-Smith Garden Design, to create a show garden and public engagement activity which was exhibited at the 2015 Royal Horticultural Society (RHS) Flower Show Tatton Park, UK. The aim of the activity was to engage a new audience with our research and to promote the field of photonics to the public within the context of the United Nations' 2015 International Year of Light and Light-based Technologies (IYL 2015) ${ }^{1}$. This paper charts the development of the project and outlines some of the benefits and challenges experienced by the team during the process. New partnerships were made, both internal and external to the university to complete the award-winning project and we offer this case study in order to assist others considering participating in arts-science project partnerships. Section 2 provides the background and the aims of the project. Section 3 describes the collaborative process to design the garden and the challenges faced in this exercise. We present the team and the delivery format in Section 4. In Section 5, we outline evaluation methods that can be applied across a wide range of outreach and public engagement scenarios, and use these to assess the impact of this project. We will reflect on the strengths and challenges of the project to conclude this paper.

*mp1g09@soton.ac.uk; phone +44 23 8059 2959; orc.soton.ac.uk

Optics Education and Outreach IV, edited by G. Groot Gregory, Proc. of SPIE Vol. 9946, 994603

(C) 2016 SPIE · CCC code: 0277-786X/16/\$18 - doi: 10.1117/12.2236977 


\section{BACKGROUND}

\subsection{Public Engagement with Research}

The 2015 RHS Flower Show Tatton Park project was possible because of the supportive environment within UoS towards Public Engagement with Research (PER). UoS engages the public with its research to fulfill a number of different obligations; amongst these is the Research Council UK's Concordat for Engaging the Public with Research ${ }^{2}$, which recognizes that public research is funded by the general public and that they should therefore have the opportunity to be engaged with that research. PER is defined by the UK's National Coordinating Center for Public Engagement as " $a$ two-way process, involving interaction and listening, with the goal of generating mutual benefit", and has created a dynamic environment for new collaborations.

To realize PER, a number of internal collaborations have been made between institutional departments, research staff and students, public engagement leaders and marketing officers; these internal collaborations work towards demonstrating that the research and its communication to target audiences have been successful. In addition, existing external partners, such as the UoS consortium membership of the European Union's Horizon 2020 project Photonics $4 A l^{4}$, have benefitted from these internal collaborations. Attending the RHS Flower Show Tatton Park provided an excellent opportunity for UoS to disseminate and promote a photonics outreach kit created by the EU project, the EYEST Photonics Explorer Education kit ${ }^{5}$.

\subsection{Reflecting Photonics: motivations and aims}

In 2014, award-winning landscape designer Helen Elks-Smith visited UoS with her son who was considering studying Physics at the university. The visit was made during an open day which included a laser light show, the Light Express Roadshow ${ }^{6}$, whose aim is to promote the study of photonics. In the laser show there was an interactive demonstration in which visitors were given strips of diffraction grating to look through. Elks-Smith was fascinated by the diffraction grating which her son gave her and as a result decided to create a garden based on photonics when she responded to the call of the RHS Flower Show Tatton Park to create a show garden to celebrate IYL 2015. Elks-Smith contacted two different people from two distinct departments within UoS, namely Standen, the Marketing Manager from the Optoelectronics Research Centre (ORC) and John, the Public Engagement Leader from the Department of Physics and Astronomy (P\&A). Elks-Smith, ORC and P\&A all had slightly different aims for working within the partnership which formed, however all wanted to create a high quality artefact and experience for its audience. The goals of the PER work at the garden show were three-fold:

- To engage a new public with the research of the UoS through a creative collaboration between the UoS and an external organization.

- To reach audiences who do not necessarily engage with science, technology, engineering and mathematics (STEM) outreach activities, and particularly with female influencers within families to raise the profile of women in photonics.

- To inspire greater interest in physics and photonics.

These aims will be explored further in the paper.

\subsection{Funding and support}

The project's success relied upon a new informal management team formed within UoS, adequate funding, and marketing support. The new team consisted of Standen, John, Posner - director of a student-led outreach program, the Lightwave Roadshow ${ }^{7}-$ and the UK's Engineering and Physical Sciences Research Council's (EPSRC) Centre for Innovative Manufacturing in Photonics (CIMP) ${ }^{8}$, including research center director, Brambilla. The team provided access to academics with vested interests in PER, postgraduate students with expertise on delivering outreach and PER activities, and staff with significant experience in managing both PER and public communications projects.

Funding for the project was provided by the EPSRC CIMP, a center set up to research advanced manufacturing of new photonic materials, fibers and components. The center was established to proactively engage with and support the photonics industrial base in the UK, and funding for the project was agreed in order to reach new audiences and forge new partnerships with national bodies. 
The project also benefitted from professional marketing support through Standen, the CIMP's Research Relationship and public relations officer. Through this role she has experience with liaising closely with PER and outreach teams as well as with researchers to devise and create events that will position the research story in the most successful way. This has enabled a number of innovative activities during IYL 2015, including the presence of a student-delegation at IYL 2015 opening ceremony in Paris, France ${ }^{9}$ and presenting a 5D data storage crystal encoded with the Universal Declaration of Human Rights to UNESCO during the plenary session of the IYL 2015 closing ceremony ${ }^{10}$.

\section{THE GARDEN}

This section covers the collaboration process of the design and manufacture of the garden, and describes the garden elements and the science tent that were employed to engage the public with photonics research.

\subsection{Garden design}

Further to initial contact, Helen Elks-Smith and Kate Hart from Elks-Smith Garden Design (Elks-Smith) visited UoS to meet with John and Standen and learn more about photonics. The visitors were given a tour of the university's cleanrooms and shown by researchers different processes for manufacturing fiber optics and integrated photonics circuits - Figure 1 (a). John and Standen provided Elks-Smith with design ideas throughout the process of the garden design and gave them written explanations of the physics behind fiber optics technology; these technical elements were included in the garden proposal for the RHS. John and Standen also produced information leaflets on the physics and engineering of the underlying fiber optic research; this information was included in a handout with information about the garden design and planting that was handed out to the general public.

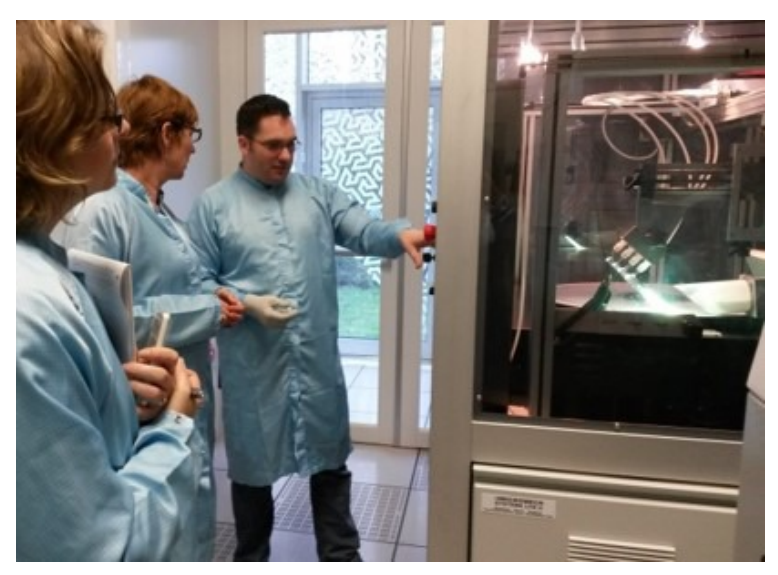

(a)
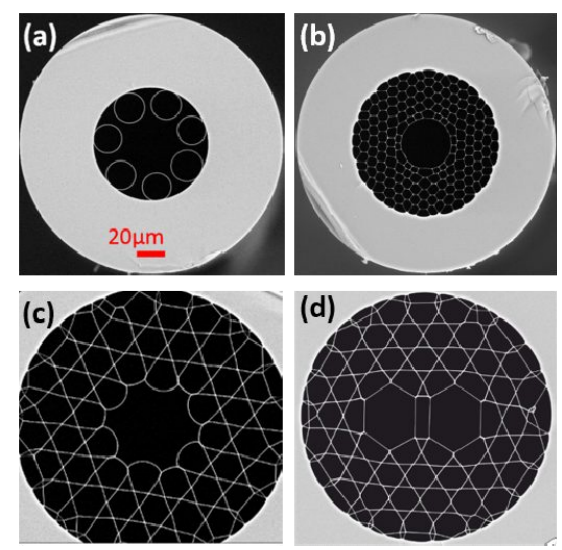

(b)

Figure 1. (a) Garden designers Helen Elks-Smith and Kate Hart visited the ORC cleanrooms facilities as part of the design process; here Dr. C. Holmes demonstrates Flame Hydrolysis Deposition, a cleanroom process to fabricate silica-based planar photonics circuits. (b) Research at the ORC in hollow-core fibers for the next generation of optical fibers inspired the design of the pavilion (fibers a-d are referenced in this sequence) ${ }^{11-14}$.

The garden was designed by Elks-Smith, and built by landscapers Turf n' Earth. The garden design, production and exhibition was supported by a collaboration between ORC, which sponsored and promoted the garden, and P\&A, which helped build the garden and lead the PER element of the science communication. The garden was designed to reflect the world-leading research in optical fibers at UoS, hence the name Reflecting Photonics. The research in novel hollow-core fibers - Figure 1 (b) - in which more than $99 \%$ of the light is guided in air thus making these exciting new candidates for applications in telecommunications, high power laser delivery and gas-based optics, inspired some of the garden elements, which we present next.

\subsection{Garden elements}

The garden consisted of a pavilion with hanging Perspex panels, a well, vertical and horizontal fiber sculptural elements, plants, trees and an accompanying show tent. The pavilion was a light-filled structure, with fiber-optic preforms set into a well at its center. The well was suggested by Standen and manufactured by Elks-Smith. The preforms were provided 
by the ORC. The side panels of the pavilion were manufactured by the mechanical workshop of P\&A and consisted of Perspex rectangles - see Figure 2 (a). The pavilion was brightly colored and unusual, drawing the audience's attention from afar to the show garden; many of the audience members wanted to know why the Perspex seemed to fluoresce and this question allowed the public engagement team to talk about total internal reflection using the edge-lit panels to illustrate how light travels through a medium.

The design elements also included vertical Perspex rods with diffraction gratings rolled up inside that separated the constituent colors of the sunlight spectrum - see Figure 2 (b). Over 20 types of flowers were selected - including Hydrangea paniculata 'Early Sensation', Verbena officinalis 'Bampton', and others - to reflect the spectrum of visible color. A path was designed as a metaphor for a wave-form of light travelling inside fiber optics - see Figure 2 (c). The designer used acrylic tubes protruding from earth mounds to reflect the fact that our telecommunications fibers are buried underground.

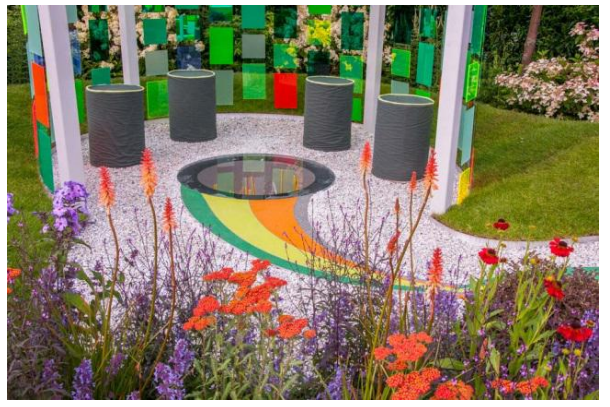

(a)

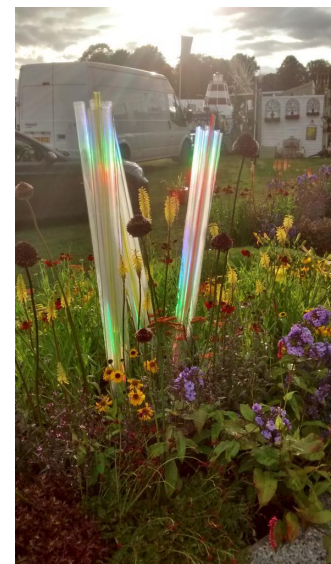

(b)

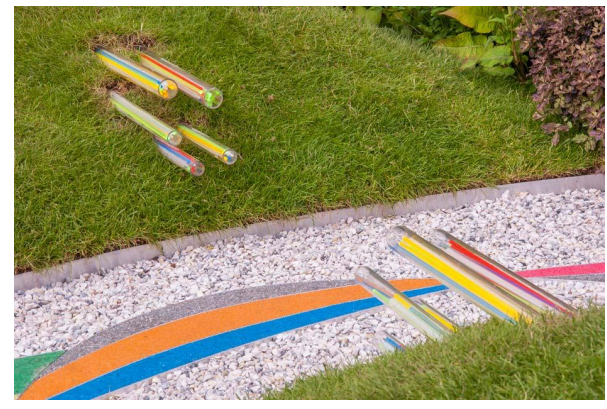

(c)

Figure 2. (a) The pavilion and the fiber optic well. The vertical Perspex sheets can be seen hanging from the pavilion. (b) Vertical Perspex rods with diffraction gratings wrapped inside were placed amongst the colorful flowers in the garden. (c) View of the rainbow path and the Perspex optical fiber rods protruding from the ground.

\subsection{Show tent}

The show garden space included a tent, shown in Figure 3 (a), where researchers set up experiments to engage the public with their research and the underlying science. These included (i) a Tyndall-Colladon demonstration of total internal reflection through a water stream, (ii) fiber optics research samples (glass and 3D printed versions), (iii) straight and bent Perspex rods with laser pointers attached to the end, to demonstrate total internal reflection, (iv) an EYEST Photonics Explorer kit with hands-on experiments, (v) handouts promoting the garden and supporters (EPSRC CIMP, Photonics4All bookmarks \& pencils), and (vi) survey-competition forms.

There were also banners advertising Lightwave and the EPRSC CIMP. Two of the researchers, one male and one female, occasionally wore their cleanroom suits to use as a prop to talk about their work environment. Posner is shown wearing his suit in Figure 3 (a). IYL 2015 3D printed keyrings showcasing van Putten's research - Figure 3 (b) - were given as rewards for completing quizzes; more details will be presented in section 5 . Videos on 3D printing, fiber fabrication and integrated photonics fabrication were played on a portable computer during the event. 


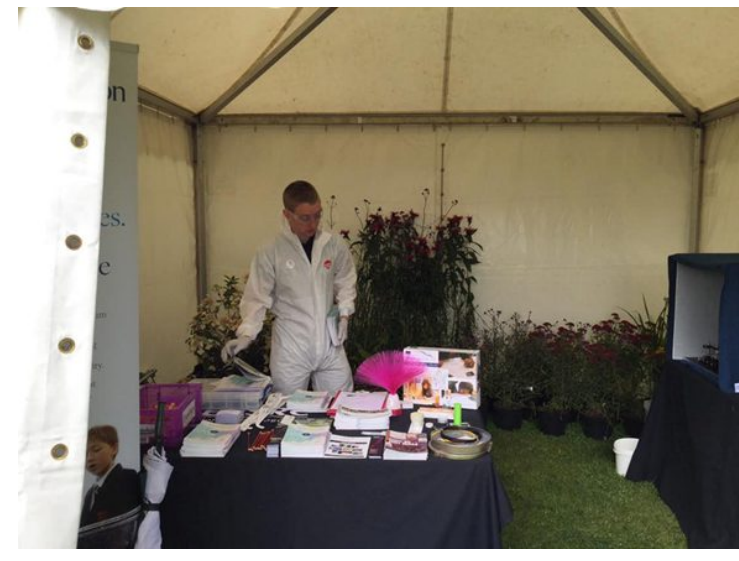

(a)

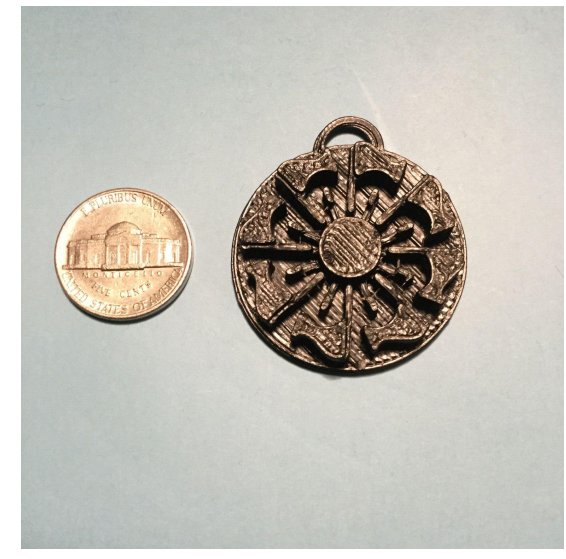

(b)

Figure 3. (a) View of the inside of the show tent. Posner is preparing handouts in a cleanroom suit. (b) IYL 2015 3D-printed keyrings showcasing van Putten's doctoral research were used as gifts for visitors completing a quiz and survey.

\section{THE PUBLIC ENGAGEMENT TEAM}

\subsection{Team composition}

A team of researchers was funded by the EPSRC CIMP to engage with the public in the garden. The Public Engagement Team from UoS consisted of academic researchers, university staff and postgraduate research students, both male and female to ensure gender diversity. These were

- Public Engagement Leader, Pearl John

- ORC Marketing Manager, Deanna Standen

- Royal Society Research Fellow, Natalie Wheeler

- Postgraduate Research Students: Matthew Posner - director of the Lightwave program at the time of the event, Tina Parsonage, Nathan Soper and Lieke van Putten.

Over three days of the week-long show, the researchers spoke with the media and staffed the garden to engage the public with their research. The overarching aim was to influence a positive change in the attitude of the people viewing the Reflecting Photonics installation towards physics and photonics. All of the postgraduate students were chosen for their extensive experience working in photonics outreach through the Lightwave Roadshow. However, further training was required and we discuss this in the following section.

\subsection{Language training}

In a report entitled "Not for People Like Me"15, Macdonald argues that STEM outreach and engagement activities have a limited impact on girls and other young people who are under-represented in the STEM workforce. The report recommends a fresh approach for people in STEM areas by using adjectives to describe their personalities and aptitudes, rather than action-oriented vocabulary to describe their jobs. John trained the demonstrators to use adjectives rather than verbs to describe themselves and their work when talking to the public, and in particular to women. Despite the training, John did not notice any demonstrators use this new approach when observing interactions with the demonstrators and the public. This different use of language does not come naturally to most and everyone involved may need further training and opportunities to apply and internalize it.

\subsection{Delivery}

Before the event, Standen worked with Elks-Smith on the design of the well which incorporated fiber preforms and she was present during the installation of the garden a few days before its opening to prepare the well. Wheeler and Standen attended the media launch for the show to promote the research which had inspired the design of the garden and they distributed diffraction gratingsglasses to the press; see Figure 4 (a). The diffraction gratings were an enjoyable point of 
interest as most had not looked through them before to see how sunlight and artificial light could be split up; see Figure 4 (b).

The students and John worked in the garden for two days talking to the public during the show ; see, for instance, van Putten engaging with the public in the garden in Figure 4 (c). All the demonstrators worked tirelessly answering all manner of questions, which included not only questions about their research but also detailed botanical questions. Posner prepared a 'cheat sheet' on the plants in the garden, which was desperately needed as often the scientists, albeit not horticulture specialists, were the only demonstrators in the garden and were expected by the visitors to be able to talk about the planting with expertise. The discussion often intertwined talking about flowers and research, to an extent that we were not expecting.

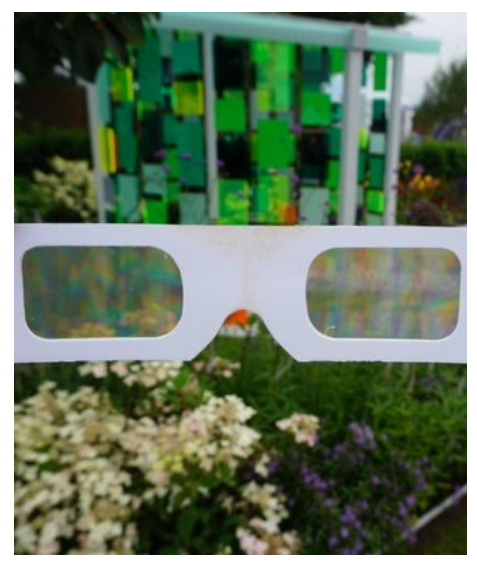

(a)

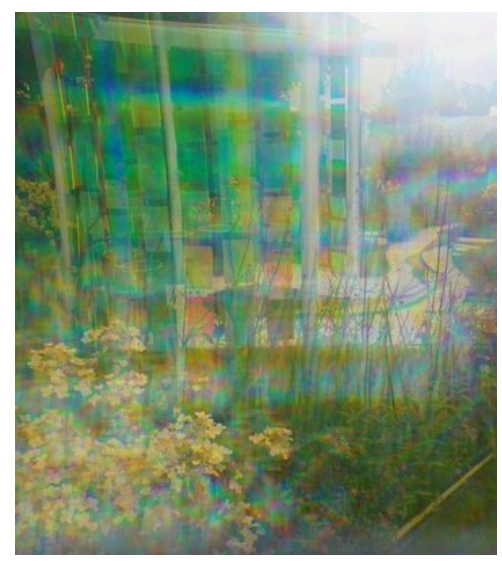

(b)

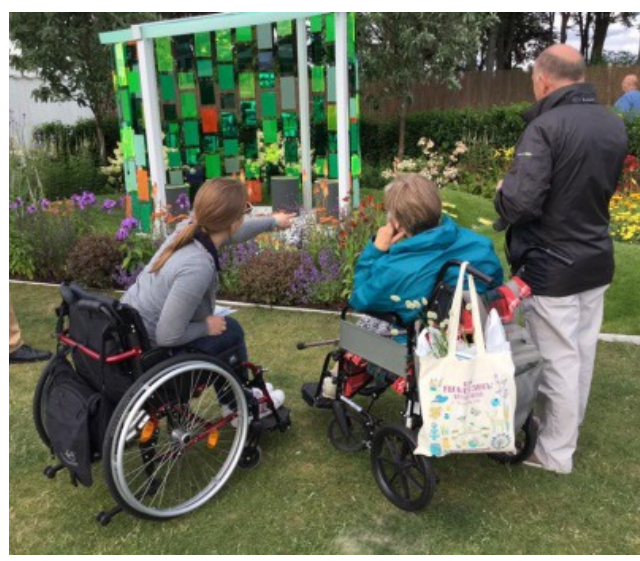

(c)

Figure 4. (a) Diffraction grating glasses were given as handouts during the press day and the show days (Picture credit: Cheshire Life ${ }^{16}$ ) (b) The garden seen through diffraction gratings sparked interesting discussions (Picture credit: Cheshire Life $^{16}$ ). (c) van Putten (left) engaging with visitors in the garden.

The delivery was observed and recorded by John, to offer feedback to the students doing the PER. For example, John observed that van Putten has a very relaxed manner, speaks slowly and clearly and adjusts the information she is given to meet the level of those to whom she talks with ease. John noticed whilst observing the event that people appeared to stay far more engaged and were willing to have longer conversations with her than with the other demonstrators. van Putten is also a wheelchair user and it was noted that visitors who are wheelchair users themselves, or have mobility issues, would often approach her, rather than the other demonstrators, to talk.

\section{EVALUATION}

Approximately 80,000 participants were expected to attend the 2015 RHS Flower Show Tatton Park ${ }^{17}$ and a much larger population to engage with it through the media. In this section, we present a number of metrics and tools employed to evaluate the impact of our activity, and reflect on challenges and routes for improvement.

\subsection{Exploiting media and social media}

The RHS Flower Show Tatton Park is an annual national event with a broad appeal to the general public. The show was featured on national and regional television (TV) and press, including national weather reports, and the national channel BBC2's show "Gardeners' World" aired at prime-time TV spots. The PER team engaged with the press during the press day and the festival; Posner is seen in Figure 5 (a) in discussion with a $\mathrm{BBC} 2$ producer during filming. Based on the average viewing figures for Gardeners' World, approximately 3 million people saw the Reflecting Photonics garden, and through this, had exposure to the concepts of 'photonics'. We have recorded 2 features of the garden on national TV ${ }^{18,19}$, 5 features in national \& regional general press ${ }^{20-24}$, and 9 features in specialized (horticultural, photonics) press ${ }^{25-33}$. A number of blog posts were written on the garden, and in addition it was promoted heavily through the communication channels of $\mathrm{UoS}^{34,35}$ and the garden design partners ${ }^{36,37}$.

We also took photographs to document the activity and provide live updates on social media. Complementary to the PER activity taking place in the garden, Standen promoted the event away from the show and encouraged people through 
social media to vote for the garden in the People's Choice Award competition. Working in a new environment permitted exposure to non-traditional audiences on social media, through the RHS Twitter account for instance - see Figure 5 (b). Analytics tools on social media permit to quantify the reach of the social media activity; there were over 75,400 Tweet impressions on social media during the show, the most popular Tweet reaching 50,800 impressions as shown by Twitter analytics - see Figure 5 (c). The high level of exposure and social media activity, combined with the staffing of the garden, was ultimately what we believe led the garden to win the People's Choice Award for Best Large Garden.

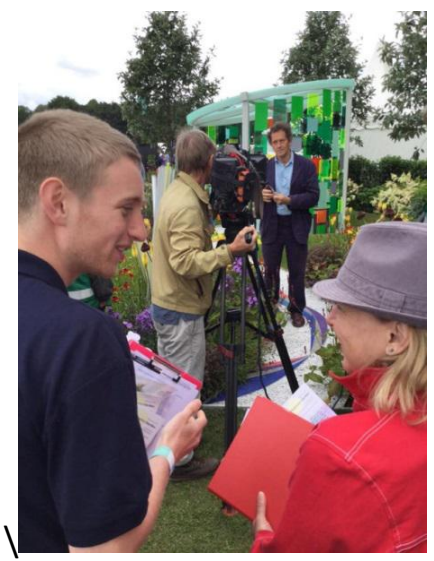

(a)

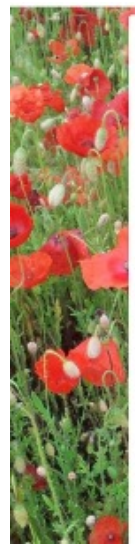

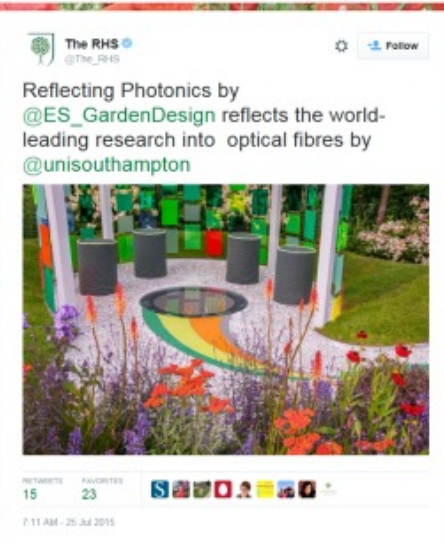

(b)

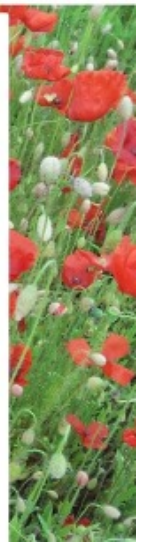

Jul $2015 \cdot 31$ days

TWEET HIGHLIGHTS

Top Tweet earned 50.8K impressions

We've won people's choice best garden for Reflecting \#Photonics @tatton_park @IYL2015@unisouthampton pic.twitter.com/MjgeAMz7iG

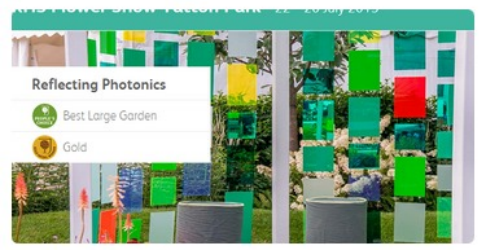

(c)

Figure 5. Overview of media and social media interaction. (a) Posner presenting the Reflecting Photonics garden to BBC2 production team of the program Gardeners' World. (b) A Tweet sent from the RHS about the Reflecting Photonics garden, reaching non-traditional audiences. (c) Twitter analytics provide insight into reach of social media activity; this Tweet earning 50,800 impressions.

\subsection{Impact of the PER activity}

To evaluate the impact of the PER activity - i.e. the reach and significance of the activity - we employed a mixed methodology using quantitative and qualitative tools. This was done in practice by handing out giveaways. One can work towards assessing the 'reach' of an activity quantitatively by considering the total number of items handed out. However, by further classifying these items into different categories, one can also evaluate the 'significance' of this interaction. We have proposed in a previous report 4 levels of significance ratings ${ }^{7}$, that we adapt to this project. These are:

1. General interaction with garden (garden information leaflets)

2. Scientific interaction in the garden and tent (diffraction gratings)

3. Pitched scientific and educational interaction in the science tent (Photonics4all bookmarks and pens)

4. Demonstration of assimilation of knowledge or change of behavior (IYL 2015 3D-printed keyrings)

The different types of handout items map the depth and length of discussion with visitors. During the two days when the PER team was exhibiting in the garden, we interacted with over 2,000 people, with 400 of whom we had a conversation based on our research. Over the same period in the science tent we handed out 93 bookmarks and 80 pens promoting Photonics4All. 42 people had lengthy (10-15 minutes) conversations with researchers and completed and returned an evaluation survey and competition entry, earning them an IYL 2015 keyring - see Figure 3 (b). Figure 6 summarizes the reach and significance of the PER activity during the two days of exhibiting the garden. Greater accuracy in determining how many people we have spoken to is still required, in particular for the 'low-significance' interactions. 


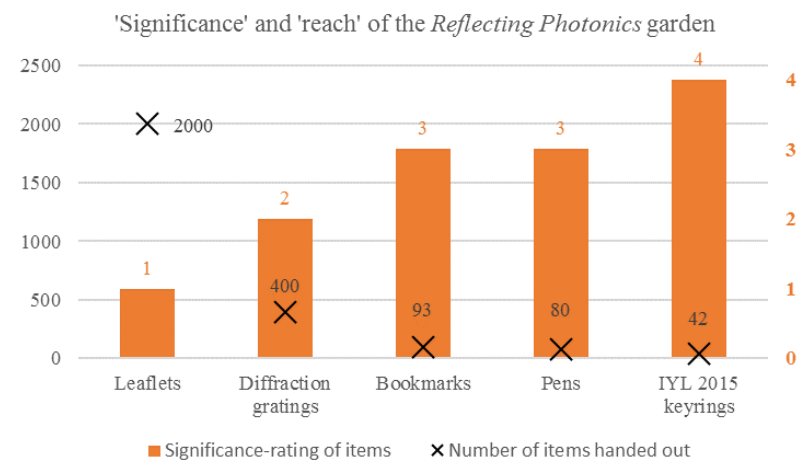

Figure 6. Mixed qualitative and quantitative assessment of the Reflecting Photonics garden. Reach is indicated on the lefthand axis and the 'impact'-index is indicated on the secondary right-hand axis.

The surveys provided details of the demographics of the audience with whom we engaged. Figure 7 (a) shows that a majority of those who visited the tent and completed the survey were female. This was consistent with the general audience numbers, a majority of whom were female. Figure 7 (b) shows that the vast majority of the participants were between 44-65 years. In addition, we worked with approximately 60 children under the age of 12 years doing hands-on demonstrations; however, this was not shown in the survey statistics. In the following section we will describe how the surveys were used to record assimilation of knowledge and change in attitude.

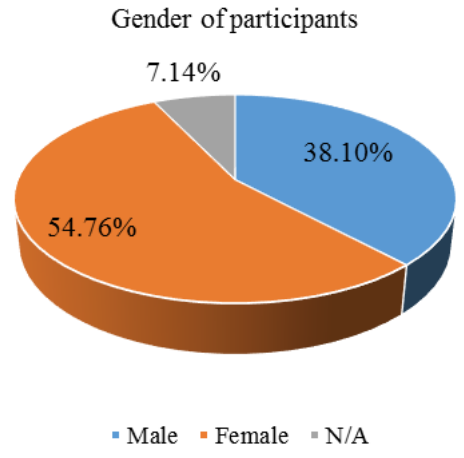

(a)

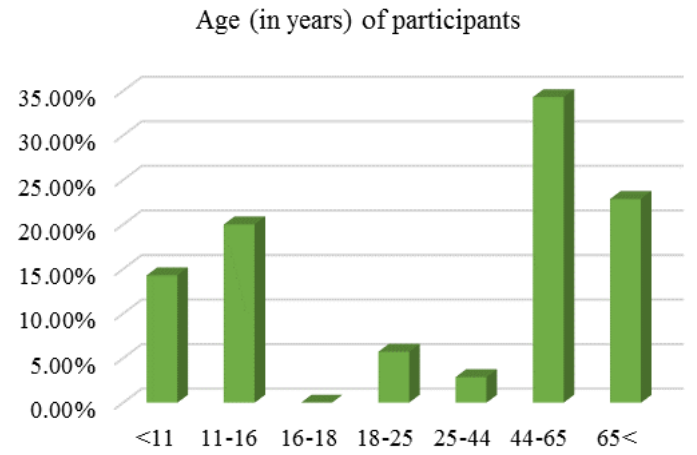

(b)

Figure 7. Demographics of population surveyed by (a) gender, and (b) age (in years).

\subsection{Assimilation of knowledge}

Aims of this project were to raise the profile of photonics and inform the general public on the science and technology of fiber optics. We set out to achieve these by giving the public the chance to participate in a quiz to test their understanding of the subject areas the PER team presented. The majority of responses to our quiz demonstrated that those who took part did learn about the above. We note though that many people were heavily coached in completing the quiz, especially the children, so the results of the quiz cannot be considered as an accurate.

The public was also offered the opportunity to answer a survey question, "Do you think you've learned anything from the Reflecting Photonics garden?" The results were insightful, and a selection of responses is shown in Table 1. Generally, people said they learned about the applications of current laser and fiber technologies (data transmission, power requirements for the internet, etc.) and fundamental sciences (refraction). We note that 'photonics' was not mentioned very often. This suggests that in future events such as these, we should link research of fiber optics into the wider research field of photonics, by explaining, for instance, how fibers are used in a wider range of applications such as manufacturing and imaging. A summary of our initial intended learning outcomes, audience responses and topics associated are presented in Table 1. 
Table 1. Intended learning outcomes and topics assimilated by the audience from the Reflecting Photonics activity; the middle column presents a selection of quotes of what the audience said they had learned from the interaction with the PER team.

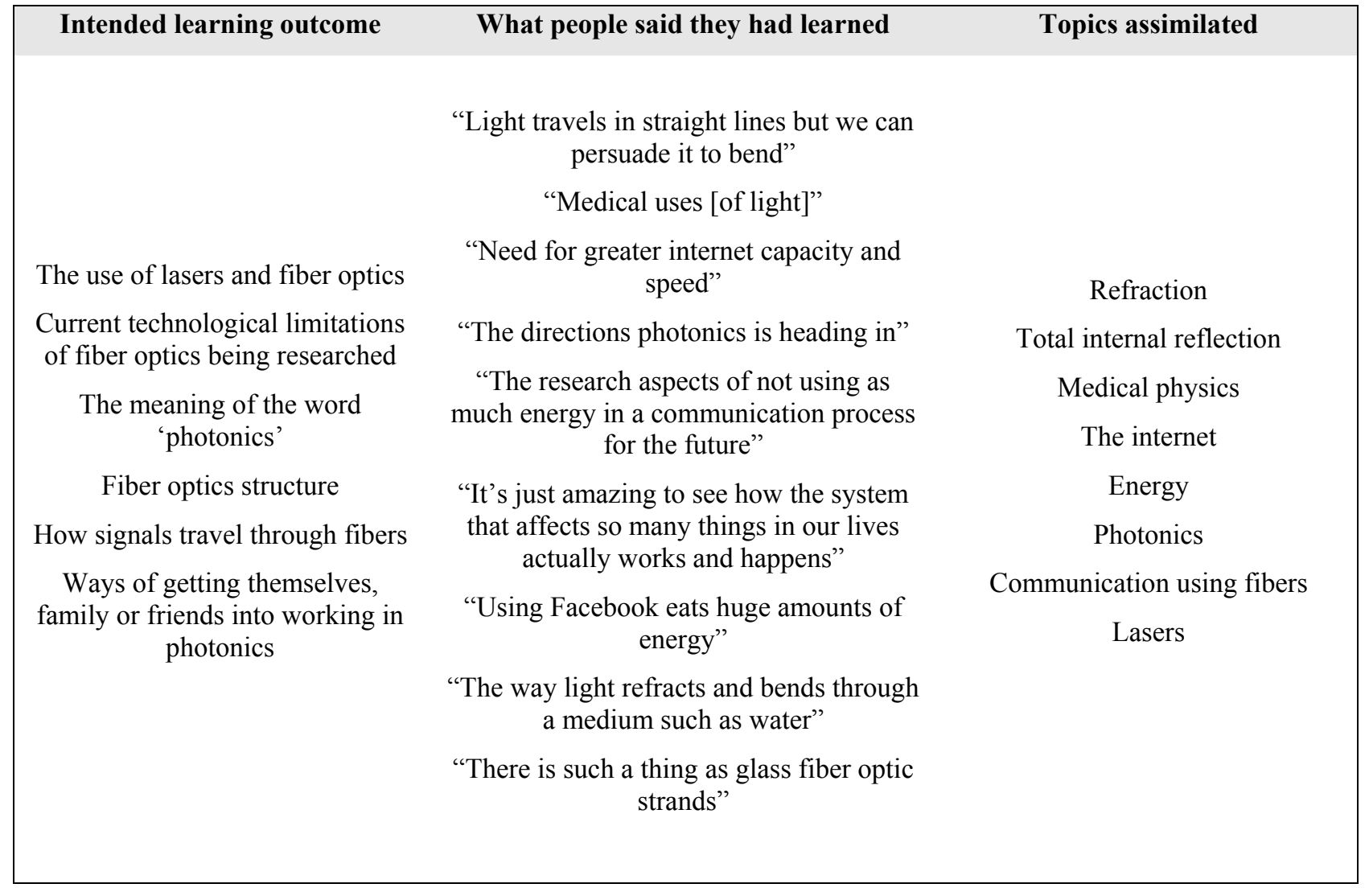

\subsection{Change of behavior}

Core to the exercise of PER is being able to obtain feedback regarding the opinions of participants about their interactions with us, and for us as researchers, to be willing to be influenced by our own public engagement experiences. Observations and surveys were carried out to observe the change of behavior, and we discuss the findings in this subsection.

People's attitude towards photonics, physics and scientific research on the whole varied considerably, and we illustrate this with a selection of observed responses in Table 2. Some observations (Table 2, \#1-6) indicate that some people were unwilling or disinterested to learn about physics. It was observed that some members of the public lacked confidence in their understanding of science (Table 2, \#5), and this type of response was mostly heard from women. John challenged this response by saying that we specifically wanted to talk to women precisely since they tended to exhibit a lack of confidence and that they actively put off younger girls from studying physics; this approach usually pulled the visitor in to have a more in-depth positive discussion on girls in physics and why they had lost their confidence, or interest in the subject. We did though have approximately 15 visitors who were retired physicists, telecommunications engineers and academics visit the tent to talk to the researchers about their work. A positive change of attitude was observed and recorded (Table 2,\#7,8). Overall, it was impossible to interest absolutely everyone and it is important to accept that the visitors were after all at the show to see gardens and were focused on horticulture. We note that having a positive friendly approach whilst demonstrating allowed one to challenge immediate rejections of interest, and engage in a discussion. 
Table 2. Selected observations, comments and conversations between the PER team (Q, questioning) and the visitor to the garden (A, answering).

\# Comments, observations, conversations

Q: Are you interested?

1 A: Visitor: No I am not scientifically minded.

Q: You don't need to be.

A: Visitor: No thank you.

2 Q (to female teenager, Year 11): Have you done the electromagnetic spectrum at school?

2 A: Yes, I know far too much about all that!

Q: Can I tell you about our research?

3 A: No. No. I am interested in the plastic though. (This comment enabled a discussion on why the edges of the plastic were illuminated).

4 "It's \{the research $\}$ lost on me dear, as always" (male visitor)

5 A young girl aged 7 was interested and happy to be shown the experiments - but her mother was not. She was actively disinterested and took her child away from the tent. (Observation by Soper).

6 As soon as I said the word 'physics' to women a number of them said 'talk to my husband'.

7 "I am a lot more interested than I was."

8 One lady told her friends how amazing it was that her voice was turned into light to be sent down a glass cable then back to the other phone. She said, "I never cease to be amazed even at a flower show!"

The surveys provided a more systematic way to assess the audience's change in knowledge and attitude. 39 surveys were used in the analysis. The audience members were asked to rate the garden on a 5-point positivity scale (with ' 5 ' being most positive). The survey also asked "How likely were you/are you to recommend studying physics and optics to a friend or family member?" and to give an answer before and after the interaction.

The attitudes towards the garden were very positive. The completed questionnaires indicate that people gave the garden an average rating of $4.6 / 5.83 \%$ of the people with whom we successfully engaged and who completed the survey in full had a positive change in attitude towards photonics and would recommend studying or working with photonics to a family or friend; $17 \%$ of respondents had a 4-point positive increase. No negative changes of attitudes were recorded. The survey responses are summarized in Figure 8. It is important to note that the team had limited training in social science methods and that this experience was beneficial to learn about different aspects of evaluation, and that more rigorous ways of collecting and processing survey data may be required.

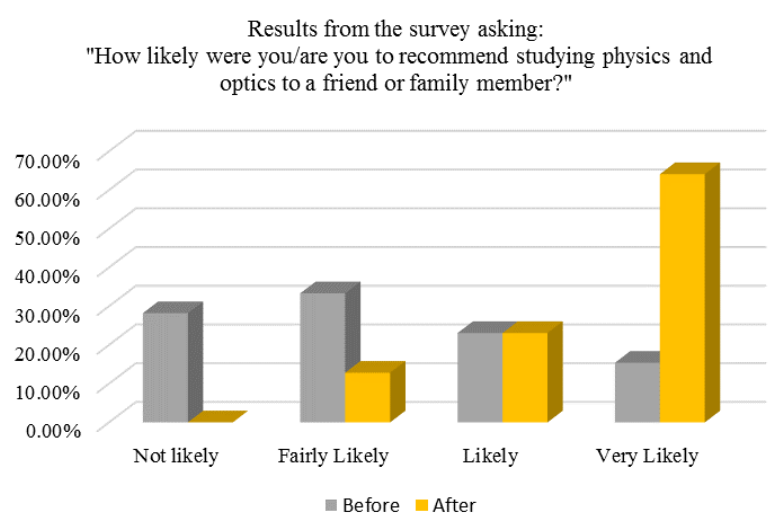

Figure 8. Change of attitude recorded from the surveys before and after interaction with the public engagement team.

\section{LESSONS LEARNED}

Much of the impact of the event came from the challenges associated with the project and the lessons learned by the project leaders. In this section, we offer the reader some of the lessons learned to assist in the successful planning of large collaborative projects. 


\subsection{Challenges working with external collaborators}

There was an important lesson learned by the authors as a result of working in new partnerships in new ways. The project was more complex than we anticipated and we would have benefitted from a memorandum of agreement between Elks-Smith (the garden design company) and UoS. A formal contract with external companies to control respective parties' involvement would be beneficial; we did not for instance expect our scientists to be responsible for talking about garden planting and horticulture during the event.

Misunderstandings occurred between Elks-Smith and the authors because the designer was unaware of the internal financial structure of UoS. For example, the project could not pay for the Civil Engineering department to sign off the safety of the construction of work produced by P\&A; work done by another department would have incurred a real charge for the project which had not been budgeted for. Upon reflection, the authors realized that Elks-Smith was used to working collaboratively with other designers and treated the university partners similarly.

While John and Standen both had creative backgrounds, which were used to make suggestions for designs for elements of the garden, neither had the technical experience of making external structures. There were communication problems and incorrect assumptions on both sides on who was responsible for creating what as a result of creative brainstorming. These problems could have been avoided by a longer process of discussion with a written agreement to follow.

\subsection{Benefits of forming institutional collaborations}

Like many other universities in the UK, UoS operates an internal market structure so P\&A, the ORC and the CIMP are all funded separately, with distinct budgets and access to facilities and services. It would have been prudent to have formed an agreement between internal partners for clarity. It is worth noting that if we had had complete clarity about what the project entailed, it would potentially have been considered too costly in terms of time and expense; there are benefits to inexperience. Completing the project led to internal partnerships being formed between P\&A and ORC staff, and between staff and students in the ORC and P\&A. Stronger partnerships were also forged between P\&A and the EPSRC CIMP management who financed part of the project.

\subsection{Impact on authors}

All members of the PER team developed important communication and presentation skills throughout the event. Soper noted that a majority of questions from the public were of a very similar nature and pattern; an effective strategy proved to be having a 'nearly rehearsed' set of answers in order to address the public's queries quickly and effectively. The team gained critical observation skills, by being able to rapidly identify and tailor a dialogue based on certain criteria, such as age and level of education, in order to ensure maximum takeaway benefit from each conversation. Questions such as "Do you have a background in physics or engineering?" were particularly useful to gauge the knowledge of the public and pitch a message suitably. It was noted by one of the garden designers that the PER team's communications skills had contributed significantly to the garden winning the 'People's Choice Award for Best Large Garden'.

Table 3. Skills acquired by different actors in the project.

\begin{tabular}{cc} 
Skills developed & Role \\
\hline Communication \& presentation skills & PER team \\
\hline Observation skills & PER team \\
\hline Event \& team management & $\begin{array}{c}\text { Lightwave director, public engagement leader, } \\
\text { marketing officer }\end{array}$ \\
\hline $\begin{array}{c}\text { Production of documentation (risk assessments, } \\
\text { information leaflets, flower description sheet) }\end{array}$ & $\begin{array}{c}\text { Lightwave director, PE leader, marketing officer } \\
\text { Working with internal collaborators }\end{array}$ \\
\hline Working with external collaborators & $\begin{array}{c}\text { Lightwave director, public engagement leader, } \\
\text { marketing officer. }\end{array}$ \\
\hline Evaluation methodology & Public engagement leader, marketing officer \\
\hline Adapting to unexpected situations & Public engagement leader, marketing officer \\
\hline
\end{tabular}


Further skills were developed specifically by the student and staff leaders of the activities, and a summary of these skills acquired by each player in this collaboration is presented in Table 3. Work is ongoing to utilize more rigorous ways for evaluation. Simple digital tallies are now used in PER activities to determine accurate numbers of audience members spoken with, and we are researching social science methods for qualitative data collection and evaluation. More effective ways of gathering data from more participants are being explored in parallel. While all team members were interviewed by John shortly after the event to gather information on the impact of the project on them, we recognize that a far more rigorous manner of self-assessment and formal methods of self-reflection are required for future projects.

\section{CONCLUSION}

The Reflecting Photonics show garden won a Gold Medal for its design and garden elements. The high level of exposure and social media activity, combined with the staffing and engagement of the garden, is what we believe ultimately led the garden to win the People's Choice Award for Best Large Garden. The project team members subsequently won the South East England Physics Network Public Engagement Innovation Project Award. Working with a landscape designer and the RHS provided a novel platform to engage the public with photonics and university research. We will remain open to taking part in more creative collaborations. We will continue to look for opportunities to work with influencers to the young, particularly mothers and grandmothers, to combat gender stereotypes and encourage more women into physics. As a result of taking part in this project we conclude that reaching new audiences is worthwhile and beneficial, to all involved.

\section{ACKNOWLEDGEMENTS}

The authors acknowledge support from the EPSRC-funded Centre for Innovative Manufacturing in Photonics (grant $\mathrm{EP} / \mathrm{H} 02607 \mathrm{X} / 1$ ) and from the Optoelectronics Research Centre for sponsoring the garden and for funding researchers to staff the garden and engage with the public; the University of Southampton department of Physics and Astronomy for manufacturing the garden Pavilion; the European Union's Horizon 2020-funded Photonics4all research and innovation program under grant agreement No 644606 for providing Photonics Explorer kits and outreach tools to disseminate; the OSA, SPIE and IEEE Photonics Society for funding outreach kits through the 2015 International Year of Light student chapter outreach activity grants; and Thomas Jefferson-Brain for helping analyze the data collected in the surveys.

\section{REFERENCES}

[1] UN General Assembly, Resolution 68/221, "International Year of Light and Light-based Technologies, 2015.", $\mathrm{A} / \mathrm{RES} / 68 / 221$ (2014).

[2] "Concordat for Engaging the Public with Research: RCUK.", RCUK, <http://www.rcuk.ac.uk/RCUKprod/assets/documents/scisoc/ConcordatforEngagingthePublicwithResearch.pdf> (5 May 2015 ).

[3] "What is Public Engagement?", NCCPE, 2016, <https://www.publicengagement.ac.uk/explore-it/what-publicengagement> (6 August 2016$)$.

[4] "Photonics4all.", 2016, <http://photonics4all.eu/> (6 August 2016 ).

[5] “Photonics Explorer.”, EYEST, 2016, <http://www.eyest.eu/STEM-Programs/Photonics-Explorer>.

[6] “The Light Express.”, <http://www.lightexpress.soton.ac.uk/> (6 May 2015 ).

[7] Wong, N. H. L., Posner, M. T.., John, P. V., "The Lightwave Programme and Roadshow : An Overview and Update," Proc. SPIE 9793 97932V, 1-16 (2015).

[8] Standen, D., "EPSRC Centre for Innovative Manufacturing in Photonics," $<$ http://www.cimp.soton.ac.uk/> (8 August 2016 ).

[9] Standen, D., "Students attend global launch of the International Year of Light," 2015, $<$ http://www.orc.soton.ac.uk/iylopens.html> (8 August 2016 ). 
[10] Standen, D., "Universal Declaration of Human Rights preserved to 5D optical memory," 2016, $<$ http://www.orc.soton.ac.uk/udhr_iyl.html> (8 August 2016 ).

[11] Hayes, J. R., Sandoghchi, S. R., Bradley, T. D., Liu, Z., Slavik, R., Gouveia, M. A., Wheeler, N. V., Jasion, G. T., Chen, Y., et al., "Antiresonant Hollow Core Fiber with Octave Spanning Bandwidth for Short Haul Data Communications," Proc. OFC (postdeadline), Th5A.3 (2016).

[12] Chen, Y., Liu, Z., Sandoghchi, S. R., Jasion, G. T., Bradley, T. D., Fokoua, E. N., Hayes, J. R., Wheeler, N. V., Gray, D. R., et al., "Multi-kilometer Long, Longitudinally Uniform Hollow Core Photonic Bandgap Fibers for Broadband Low Latency Data Transmission," J. Lightw. Technol. 34(1), 104-113 (2016).

[13] Wheeler, N. V., Bradley, T. D., Hayes, J. R., Gouveia, M. A., Chen, Y., Sandohgchi, S. R., Poletti, F., Petrovich, M. N.., Richardson, D. J., "Low Loss Kagome Fiber in the $1 \mu \mathrm{m}$ Wavelength Region," Proc. Adv. Photonics 2016 (IPR, NOMA, Sensors, Networks, SPPCom, SOF), SoM3F.2 (2016).

[14] Wheeler, N. V., Bradley, T. D., Hayes, J. R., Jasion, G. T., Chen, Y., Sandoghchi, S. R., Horak, P., Poletti, F., Petrovich, M. N., et al., "Dual hollow-core antiresonant fibres," Proc. SPIE 9886, 988617 (2016).

[15] MacDonald, A., “'Not for people like me?' Under-represented groups in science, technology and engineering," WISE Campaign, (2014).

[16] “Cheshire Life.”, 2015, <https://twitter.com/cheshirelife/status/624530984738926592> (8 August 2016).

[17] Dowling, J., “Annual Tatton Park Flower Show draws crowds,” 2015, <http://www.bbc.co.uk/news/uk-england33612273> (8 August 2016 ).

[18] “RHS Show Tatton Park Episode 1.”, BBC2, United Kingdom (2015).

[19] “RHS Show Tatton Park Episode 2.", BBC2, United Kingdom (2015).

[20] "The best gardens from the RHS Tatton Park Show.", Telegr., 2015, $<$ http://www.telegraph.co.uk/gardening/11756207/The-best-gardens-from-the-RHS-Tatton-Park-

Show.html?frame $=3384062>(8$ August 2016).

[21] "RHS Tatton judges wowed by quality.", Chesh. Today, 2015, <http://www.cheshire-today.co.uk/34999/rhstatton-judges-wowed-by-quality/> (8 August 2016).

[22] "Photonics garden makes Light work of understanding science at RHS Show.", Chesh. Mag., 2015, $<$ http://incheshiremagazine.co.uk/photonics-garden-makes-light-work-of-understanding-science-at-rhs-show/> (8 August 2016).

[23] Green, M., "RHS Tatton Park Flower Show: Stars come out for 17th year of floral extravaganza," Chester Chron., 2015, <http://www.chesterchronicle.co.uk/news/chester-cheshire-news/rhs-tatton-park-flower-show9712682> (8 August 2016).

[24] "Best Large Garden - Reflecting Photonics - RHS Flower Show Tatton Park.", All About London, 2015, $<$ http://www.all-about-london.com/2015/07/best-large-garden-reflecting-photonics.html > (8 August 2016).

[25] "Year of Light gardens.", RHS, 2015, <https://www.rhs.org.uk/shows-events/rhs-flower-show-tattonpark/2015/year-of-light-gardens> (8 August 2016).

[26] "CED Stone Group feature among the Award Winning gardens at the RHS Tatton Park Flower Show.", BALI, 2015, <http://www.ced.ltd.uk/news/ced-stone-group-feature-among-the-award-winning-gardens-at-the-rhstatton-p> (8 August 2016).

[27] "Helen Elks-Smith Show Garden is provided light by SureSet Spectrum ${ }^{\circledR}$ at Tatton Park.", BALI, 2015, $<$ http://www.bali.org.uk/industry/news/news_article.helen-elks-smith-show-garden-is-provided-light-by-suresetspectrum-at-tatton-park.html> (8 August 2016).

[28] "International Year of Light inspires Tatton Park gardens.", Hortic. Week, 2015, $<$ http://www.hortweek.com/international-year-light-inspires-tatton-park-gardens/landscape/article/1343845> (8 August 2016). 
[29] Appleby, M., "RHS Tatton Park Flower Show winners announced," Hortic. Week, 2015, $<$ http://www.hortweek.com/rhs-tatton-park-flower-show-winners-announced/landscape/article/1357220> (8 August 2016).

[30] Morgan, I., "BALI members celebrate medals and accolades at the 2015 RHS Flower Show Tatton Park," Pro Landscaper, 2015, <http://prolandscapermagazine.com/bali-members-celebrate-medals-and-accolades-at-the2015-rhs-flower-show-tatton-park/> (8 August 2016).

[31] "SureSet Spectrum ${ }^{\circledR}$ providing light at Tatton Park.", Pro Landscaper, 2015, $<\mathrm{http}$ //prolandscapermagazine.com/sureset-spectrum-providing-light-at-tatton-park/> (8 August 2016).

[32] Wallace, J., "Optoelectronics Research Centre creates light-themed garden for 2015 International Year of Light," Laser Focus World, 2015, <http:/www.laserfocusworld.com/articles/2015/07/optoelectronics-research-centrecreates-light-themed-garden-for-2015-international-year-oflight.html?cmpid=EnlLFWAugust42015\&eid=293601660\&bid=1141658> (8 August 2016).

[33] “The winners at Tatton.”, Happy Gard., 2015, <http://www.thehappygardeners.co.uk/the-winners-at-tatton/> (8 August 2016).

[34] Standen, D., "IYL2015 Garden makes Light work of understanding science," 2015, $<$ http://www.orc.soton.ac.uk/rhs.html> (8 August 2016).

[35] "Reflecting Photonics garden wins People's Choice Award.", 2015, $<$ http://www.southampton.ac.uk/news/2015/08/garden-of-light-award.page> (8 August 2016).

[36] Johnston, G., "Providing Light at RHS Tatton Park," Sureset, 2015, <http://www.sureset.co.uk/blog/providinglight-at-rhs-tatton-park> (8 August 2016).

[37] “RHS Tatton 2015 Gold and People’s Choice.”, Elks-Smith Landsc. Gard. Des., 2015, <http://www.elkssmith.co.uk/rhs-tatton-2015-gold-peoples-choice/> (8 August 2016). 